\title{
Christian Bobin, poète désarçonnant
}

\author{
Jean Martin \\ Dr med., membre de la rédaction
}

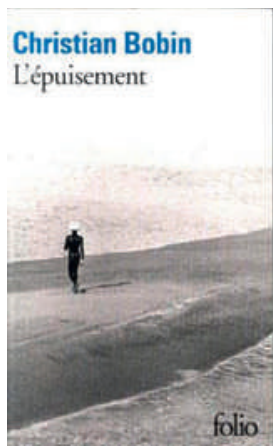

Christian Bobin

L'épuisement Paris: Gallimard; 2015. 88 pages. $9,90 \mathrm{CHF}$. ISBN 978-2-07-046244-5
Christian Bobin, né en 1951, fils d'employés de la grande métallurgie du Creusot, ville où il a toujours vécu, est une figure particulière dans la littérature poétique française. A étudié la philosophie, a aussi été élève infirmier en psychiatrie. Parmi ses essais les plus connus, Le Très-Bas, inspiré par St-François d'Assise, La part manquante, et La plus que vive, extraordinaire ode à une amie prématurément disparue. L'épuisement vient de paraître.

Bobin à mon sens ne ressemble à aucun autre. A chaque fois, je suis sous le charme d'une prose légère tout en parlant de choses graves, avec des moments paradoxaux, désarçonnants, en toute gentillesse - parfois insaisissable. Parle beaucoup d'enfance, d'adolescence, de la vie dans diverses dimensions, de la mort. Pour qui comme moi n'est pas un lecteur rapide, un ouvrage de Bobin offre en quelques heures une cure de poésie. Délicat de choisir quelques citations tant les thèmes évoqués sont divers, surprenants - procurant souvent des "Aha-Erlebnisse», comme on dit outre-Sarine.

Vivre - Goût de la solitude. "Il n'y a pas la moindre sagesse dans ma vie. Pas non plus de folie. Je ne sais pas au juste ce qu'il y a dans ma vie. La vie peut-être, simplement. Et la solitude, qui occupe ma maison à un point incroyable de sans-gêne. Elle ne laisse rien en dehors d'elle, sauf la feuille blanche. C'est lorsque j'écris que je suis le moins seul.»

"Aucune vraie rencontre ne peut se faire sans aussitôt nous défaire.» "Je n'ai jamais vécu en couple. Ce qui fait le désespoir de tant de couples, c'est un irrespect de la solitude native de l'autre. Je ne partage ma vie qu'avec des compagnons d'une discrétion exemplaire: du bleu léger éparpillé dans l'air, une plante accoudée à une fenêtre - et un miroir. Ce qui est le bien d'une personne c'est à la personne seule d'en décider, en ne s'appuyant que sur la lumière suffisante de sa propre solitude, au plus loin des convenances de pensée ou de morale.» Ecriture. "Quelque chose a lieu dont j'ignore tout et je voudrais dire cette chose. Je ne sais pas si j'y parviendrai. Les écrivains qui savent d'avance ce que sera leur livre ne sont pas des écrivains mais des créatures de Dieu atteintes par la folie du raisonnable, du sérieux, du devoir à rendre. Moi, j'ai un livre à faire pour la lumière qu'il me donnera.» «Je suis incapable de parler d'autre chose que de l'amour dont je ne sais rien. Tout ce qui est de l'ordre d'un savoir m'indiffère. Même la connaissance que j'ai de moi m'accable d'ennui profond" (cette dernière remarque rendrait-elle compte du titre du livre?).

De curieuses réflexions à consonance médicale...: «Je ne cherche jamais l'écriture. C'est elle qui me vient. C'est quelque chose qui me blesse. Ecrire, c'est se découvrir hémophile, saigner de l'encre à la première écorchure, perdre ce qu'on est au profit de ce qu'on voit.» Et: "L'écriture, par le rythme d'une voix, le mouvement d'une phrase, calme la conscience ordinaire et réveille une conscience du dessous, plus fine: l'écrivain est à la fois anesthésiste et chirurgien. Il endort l'âme avant de l'ouvrir.» "Après un grand amour, c'est comme après la mort pour ceux qui en réchappent: on s'étonne du temps qui reste. Comme ceux qui reviennent des blanches autoroutes d'un coma, on garde au fond de l'âme la douceur irradiée du grand amour.»

Enfants et parents. Bodin a son avis sur un sujet très actuel dans la littérature, générale et scientifique, des deux côtés de l'Atlantique, à savoir l'influence de la famille et du milieu dans ce qu'on devient: «Si les parents savaient à quel point ils sont pour peu dans le devenir de l'enfant, ils en seraient effrayés.» "Les enfants sont les seules grandes personnes que je connaisse. Les enfants sont des gens du voyage, des âmes de grande circulation. Les gens qui les accueillent et leur donnent asile, leurs parents, sont les hôteliers de l'enfance.» «Le vif en nous, c'est l'enfant, celui qui aime, qui joue à aimer.» Voyager sur place. "Je fais un piètre touriste, un mauvais élève de la beauté obligée. Je ne suis jamais allé ni en Grèce ni en Italie. Je vois dans la première flaque d'eau venue autant de miracles que dans ces terres gorgées de soleil et de peinture.»

A la dernière page du livre, ces phrases proches de celles des penseurs-poètes du $19^{\mathrm{e}}$ siècle des Etats-Unis - notamment Henry David Thoreau, qui cherchaient leur épanouissement dans la nature, la spiritualité, la solitude: «Je suis comme mon amie l'écriture, nomade. Moi qui ne sors presque jamais de cet appartement, je bouge énormément. Personne n'est plus relié au monde que moi dans ces jours où ma porte ne s'ouvre pas. Personne n'écrit plus que moi dans ces heures où je n'écris rien.» 